\title{
Presence and Accuracy of Drug Dosage Recommendations for Continuous Renal Replacement Therapy in Tertiary Drug Information References
}

\author{
Sean K Gorman, Richard S Slavik, and Stefanie Lam
}

\begin{abstract}
Background: Clinicians commonly rely on tertiary drug information references to guide drug dosages for patients who are receiving continuous renal replacement therapy (CRRT). It is unknown whether the dosage recommendations in these frequently used references reflect the most current evidence.
\end{abstract}

Objective: To determine the presence and accuracy of drug dosage recommendations for patients undergoing CRRT in 4 drug information references.

Methods: Medications commonly prescribed during CRRT were identified from an institutional medication inventory database, and evidence-based dosage recommendations for this setting were developed from the primary and secondary literature. The American Hospital Formulary System-Drug Information (AHFS-DI), Micromedex 2.0 (specifically the DRUGDEX and Martindale databases), and the 5th edition of Drug Prescribing in Renal Failure (DPRF5) were assessed for the presence of drug dosage recommendations in the CRRT setting. The dosage recommendations in these tertiary references were compared with the recommendations derived from the primary and secondary literature to determine concordance.

Results: Evidence-based drug dosage recommendations were developed for 33 medications administered in patients undergoing CRRT. The AHFS-DI provided no dosage recommendations specific to CRRT, whereas the DPRF5 provided recommendations for 27 (82\%) of the medications and the Micromedex 2.0 application for $20(61 \%)$ (13 [39\%] in the DRUGDEX database and 16 [48\%] in the Martindale database, with 9 medications covered by both). The dosage recommendations were in concordance with evidence-based recommendations for 12 (92\%) of the 13 medications in the DRUGDEX database, 26 (96\%) of the 27 in the DPRF5, and all $16(100 \%)$ of those in the Martindale database.

Conclusions: One prominent tertiary drug information resource provided no drug dosage recommendations for patients undergoing CRRT. However, 2 of the databases in an Internet-based medical information application and the latest edition of a renal specialty drug information resource provided recommendations for a majority of the medications investigated. Most dosage recommendations were similar to

\section{RÉSUMÉ}

Contexte : Les cliniciens s'appuient couramment sur des sources tertiaires d'information pour guider les posologies médicamenteuses chez les patients sous traitement continu de remplacement de la fonction rénale (TCRFR). On ignore si les recommandations posologiques dans ces sources couramment utilisées reflètent les données probantes les plus actuelles.

Objectif : Déterminer la présence et l'exactitude des recommandations sur la posologie des médicaments utilisés chez les patients sous TCRFR dans quatre sources d'information sur les médicaments.

Méthodes : On a dressé la liste des médicaments couramment prescrits durant le TCRFR à partir d'une base de données des médicaments en inventaire dans un établissement, puis on a défini des recommandations posologiques fondées sur des données probantes issues de la littérature primaire et secondaire. L'American Hospital Formulary System-Drug Information (AHFS-DI), le Micromedex 2.0 (en particulier les bases de données DRUGDEX et Martindale) et la $5^{5}$ édition de Drug Prescribing in Renal Failure (DPRF5) ont été évalués à la recherche de recommandations posologiques sur des médicaments utilisés en cours de TCRFR. Les recommandations posologiques dans ces sources tertiaires ont été comparées aux recommandations tirées de la littérature primaire et secondaire pour établir une concordance.

Résultats : Des recommandations posologiques fondées sur des données probantes ont été rédigées pour 33 médicaments administrés aux patients sous TCRFR. LAHFS-DI n'a fourni aucune recommandation posologique spécifique au contexte du TCRFR, alors que la DPRF5 a fourni des recommandations posologiques pour 27 (82\%) des médicaments et le logiciel d'application Micromedex 2.0 pour $20(61 \%)$ des médicaments (13 [39\%] dans la base de données DRUGDEX et 16 [ $48 \%$ ] dans la base de données Martindale, dont 9 médicaments traités dans les deux sources). Les recommandations posologiques concordaient avec celles fondées sur des données probantes pour $12(92 \%)$ des 13 médicaments de la base de données DRUGDEX, 26 (96\%) des 27 médicaments de la DPRF5 et tous les 16 médicaments (100\%) de la base de données Martindale.

Conclusions : Une importante source tertiaire d'information sur les médicaments n'a fourni aucune recommandation posologique sur des médicaments utilisés chez les patients sous TCRFR. En revanche, deux des bases de données comprises dans une application Web d'information 
those derived from the primary and secondary literature. The most recent edition of the DPRF is the preferred source of information when prescribing dosage regimens for patients receiving CRRT.

Key words: renal failure, continuous renal replacement therapy, dosage adjustments, drug information

Can J Hosp Pharm 2012;65(3):188-195 médicale et la dernière édition d'une source d'information sur les médicaments utilisés en néphrologie ont fourni des recommandations pour la majorité des médicaments examinés. La plupart des recommandations posologiques étaient similaires à celles tirées des sources d'information primaires et secondaires. La plus récente édition du DPRF est la source préférée pour l'établissement des schémas posologiques chez les patients qui reçoivent un TCRFR.

Mots clés : insuffisance rénale, traitement continu de remplacement de la fonction rénale, ajustements posologiques, information sur les médicaments

[Traduction par l'éditeur]

\section{INTRODUCTION}

$\mathrm{C}$ ontinuous renal replacement therapy (CRRT) is frequently used for critically ill patients with renal failure. ${ }^{1}$ CRRT produces less hemodynamic instability, allows for more gradual fluid and solute shifts, and better facilitates convenient titration of fluid removal than intermittent renal replacement therapy. ${ }^{2}$ The pharmacokinetics of many medications prescribed for critically ill patients are significantly altered during CRRT, which necessitates dosage adjustments to ensure that the goals of pharmacotherapy are met. ${ }^{3-6}$ Clinicians often rely on tertiary drug information resources, such as the American Hospital Formulary System-Drug Information (AHFS-DI) ${ }^{7}$ and Micromedex ${ }^{8}$ to guide drug dosing in renal failure. Specialty drug information resources such as Drug Prescribing in Renal Failure (DPRF) ${ }^{9}$ are also used in the setting of renal dysfunction to help select drug dosing regimens. However, a previous systematic assessment of drug dosage recommendations for various degrees of renal function revealed that tertiary drug information references may not be suitable for clinical use because of wide variation in the recommendations. ${ }^{10}$ The authors of a recent editorial revealed that less than $20 \%$ of currently used drugs have been studied in the setting of CRRT. ${ }^{11}$ Furthermore, it is unknown whether drug dosage recommendations for the CRRT setting are provided in tertiary drug information resources and if so, whether the recommendations are concordant with recommendations derived from the primary and secondary literature. This study was undertaken to determine the presence and accuracy of drug dosage recommendations in the setting of CRRT in 4 commonly used drug information references.

\section{METHODS}

\section{Selection of Drugs and Synthesis of Evidence- Based Dosage Recommendations}

A convenience sample of the medications most commonly used in the 27-bed intensive care unit (ICU) of an academic tertiary care hospital was identified a priori from the institu- tion's drug inventory database and an ICU quality assurance database. This list of medications was used for literature searches in the PubMed (1950-2011), Embase (1980-2011), and International Pharmaceutical Abstracts (1965-2011) databases. The literature searches targeted in vivo studies examining dosage or pharmacokinetic information for the drugs of interest for all venovenous modes of CRRT in adults. Medical Subject Headings (MeSH terms) used for the searches included "hemodiafiltration" and "hemofiltration". The generic names of the specified medications were searched with either MeSH terms or text words. When applicable, MeSH subheadings were used, including "administration and dosage" and "pharmacokinetics". Finally, text word searches were performed for "continuous renal replacement therapy", "continuous venovenous hemodiafiltration", "continuous venovenous hemodialysis", and "continuous venovenous hemofiltration". Terms referring to electrolytes, insulin, micronutrients, opioid analgesics, sedatives, vasopressors, and inotropes were excluded because dosing of these agents is frequently and readily adjusted on the basis of clinical or laboratory monitoring for efficacy and toxicity. Studies of drug removal (in patients undergoing CRRT) in the setting of toxicity were also excluded, because a drug's toxicokinetics may significantly differ from its usual pharmacokinetic properties. ${ }^{12}$

Evidence-based drug dosage recommendations in CRRT were generated by one critical care clinical pharmacy specialist (S.K.G.), who extracted recommendations from each of the included pharmacokinetic studies and created a range of recommended dosages to reflect the variation in recommendations across the studies. Dosage variability for any particular drug was due primarily to small sample sizes in the studies or, more importantly, differences in patient populations, CRRT equipment, CRRT modes, and other techniques used. Two recently published comprehensive evidence-based reviews that provided antibacterial and antifungal dosing recommendations for patients undergoing CRRT ${ }^{6,13}$ were also included, to ensure that our recommendations were consistent. The final dosage recommendations were considered the reference standard for comparison purposes in this study. 


\section{Selection of Tertiary Drug Information References}

The following tertiary drug information references were frequently used by clinicians at the academic tertiary care ICU and were selected for evaluation: the AHFS-DI (electronic access June 2011 via MedicinesComplete subscription service, Pharmaceutical Press, London, UK), 7 Micromedex 2.0 (electronic access June 2011), ${ }^{8}$ and the 5th edition of the DPRF (DPRF5). ${ }^{9}$ Two drug information databases contained within the Micromedex 2.0 application were evaluated: DRUGDEX ${ }^{14}$ and Martindale: The Complete Drug Reference. ${ }^{15}$ The Canadian Compendium of Pharmaceuticals and Specialties ${ }^{16}$ was not evaluated because it was not routinely used by clinicians in the study ICU, and a previous evaluation suggested that drug dosing recommendations in CRRT were largely absent from this reference. ${ }^{17}$

\section{Data Synthesis}

The 4 drug information resources were evaluated for the presence and accuracy of drug dosage information for all modes of CRRT by one investigator (S.K.G.), who was not blinded to the tertiary reference being evaluated. Recommendations provided in the tertiary references were compared against the reference standard evidence-based recommendations developed from the literature and were considered concordant if the total daily dose fell within the range of the evidence-based reference standard. Only maintenance dosage regimens were evaluated for concordance. Summary descriptive statistics are reported where appropriate.

\section{RESULTS}

The systematic process for selecting medications yielded a total of 33 medications used in critically ill patients undergoing CRRT (Figure 1). In addition to the previously stated exclusions, 3 other medications were excluded for the following reasons: duplicate product (piperacillin), product discontinued in Canada (ofloxacin), and database identification of a topically administered product (chloramphenicol). The literature search yielded 55 articles providing dosage recommendations for these 33 medications, ${ }^{6,13,18-70}$ from which evidence-based drug dosage recommendations were generated. The presence of dosage recommendations in the 4 tertiary drug information references and their concordance with the evidence-based recommendations are summarized in Table 1 . The following therapeutic classes of medications were included: anti-infectives, immunosuppressives, antithrombotics, anticonvulsants, and acid suppressants.

No dosage recommendations for any of the 33 drugs were provided in the AHFS-DI. Recommendations for 13 (39\%) of the medications were provided in DRUGDEX, for $16(48 \%)$

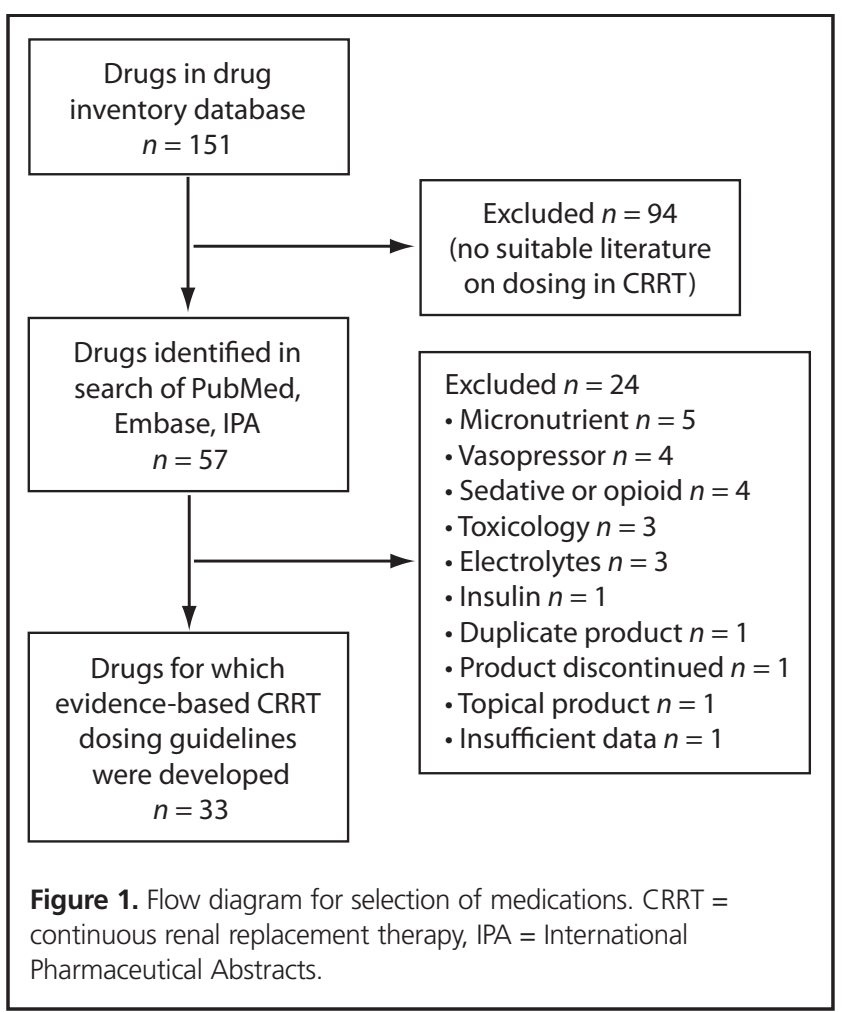

in Martindale, and for 27 (82\%) in DPRF5. The 2 Micromedex 2.0 databases together (DRUGDEX and/or Martindale) provided recommendations for 20 (61\%) of the medications. The recommendations were concordant with the evidence-based reference standard recommendations for 12 (92\%) of the 13 drugs covered in DRUGDEX, 26 (96\%) of the 27 drugs covered in DPRF5, and all 16 (100\%) of those covered in Martindale. Both cases of discordance involved recommendations for fluconazole: specifically, the dose recommended in DRUGDEX was higher than the reference standard, and the dose recommended in DPRF5 was lower than the reference standard.

\section{DISCUSSION}

To the authors' knowledge, this is the first attempt to determine the presence and accuracy of drug dosage recommendations for patients receiving CRRT in high-quality tertiary drug information references. It may be a surprise to many practitioners that one of the most prominent North American tertiary drug information resources, the AHFS-DI, does not provide any drug dosage recommendations for patients undergoing CRRT. Several factors may explain the paucity of recommendations in this reference. The AHFS-DI is a compilation of comparative, unbiased, evidence-based drug information. ${ }^{7}$ The information presented in its monographs is derived from pertinent references in the literature and expert therapeutic guidelines. ${ }^{7}$ Notwithstanding the increasing body of literature concerning pharmacokinetic alterations during 
Table 1. Drug Dosing Recommendations for Continuous Renal Replacement Therapy (CRRT)*

\begin{tabular}{|c|c|c|c|c|}
\hline Drug & $\begin{array}{l}\text { Reference Standard } \\
\text { (Maintenance Dosage) }\end{array}$ & DRUGDEX ${ }^{14}$ & Martindale ${ }^{15}$ & DPRF5 $^{9}$ \\
\hline Acyclovir & $\begin{array}{c}5-10 \mathrm{mg} / \mathrm{kg} \mathrm{IV} \\
\mathrm{q} 12-24 \mathrm{~h}^{6,18}\end{array}$ & NR & 5-10 mg/kg IV q12-24h & 5-10 mg/kg IV q24h \\
\hline Amikacin & $\begin{array}{c}5-7.5 \mathrm{mg} / \mathrm{kg} \mathrm{IV} \\
\text { q24-48h }\end{array}$ & $\begin{array}{l}\text { 4.5-10.5 mg/kg per day } \\
\text { IV divided q12-18h }\end{array}$ & NR & $7.5 \mathrm{mg} / \mathrm{kg}$ IV q24-72h \\
\hline Amoxicillin & 1000 mg PO q6h ${ }^{19,21}$ & NR & NR & NR \\
\hline Amphotericin, lipid complex & $5 \mathrm{mg} / \mathrm{kg}$ IV q24h $\mathrm{h}^{13,22}$ & NR & NR & $5 \mathrm{mg} / \mathrm{kg} \mathrm{IV} \mathrm{q24h}$ \\
\hline Amphotericin, liposomal & $3-5 \mathrm{mg} / \mathrm{kg}$ IV q24h ${ }^{13,22,23}$ & NR & NR & NR \\
\hline Basiliximab & $20 \mathrm{mg}$ IV q96h $\times 2^{24}$ & NR & NR & $\mathrm{NR}$ \\
\hline Cefepime & $\begin{array}{l}1000 \mathrm{mg} \text { IV q8h or } \\
2000 \mathrm{mg} \text { IV q12h } 12,25,26\end{array}$ & NR & $\begin{array}{c}1000 \mathrm{mg} \text { IV q8h or } \\
1000-2000 \mathrm{mg} \text { IV q12h }\end{array}$ & 1000-2000 mg IV q12h \\
\hline Cefotaxime & $\begin{array}{c}1000-2000 \mathrm{mg} \text { IV } \\
\text { q6-12h }\end{array}$ & 1000-2000 mg IV q12h & $\begin{array}{c}1000-2000 \mathrm{mg} \text { IV } \\
q 6-12 \mathrm{~h}\end{array}$ & $1000 \mathrm{mg} \mathrm{q12h}$ \\
\hline Ceftazidime & $\begin{array}{l}1000 \text { mg IV q8-12h or } \\
2000 \text { mg IV q12h } 12,28,29\end{array}$ & $\begin{array}{l}1000-2000 \mathrm{mg} \mathrm{IV} \\
\text { q24-48h }\end{array}$ & $\begin{array}{c}1000-2000 \mathrm{mg} \mathrm{IV} \\
\mathrm{q} 8-12 \mathrm{~h}\end{array}$ & $\begin{array}{c}1000-2000 \mathrm{mg} q 12 \mathrm{~h} \text { or } \\
3000 \mathrm{mg} / \text { day CIVI }\end{array}$ \\
\hline Ceftriaxone & $\begin{array}{c}1000-2000 \mathrm{mg} \text { IV } \\
\text { q12-24h }\end{array}$ & $\begin{array}{c}1000-2000 \mathrm{mg} \text { IV } \\
\text { q12-24h }\end{array}$ & NR & $\begin{array}{c}250-2000 \mathrm{mg} \text { IV } \\
\text { q12-24h }\end{array}$ \\
\hline Cefuroxime & $750-1500$ mg IV q12h"27 & NR & NR & 1000 mg IV q12h \\
\hline Ciprofloxacin & $\begin{array}{c}200-400 \mathrm{mg} \mathrm{IV} \\
\mathrm{q} 12-24 \mathrm{~h}^{6,32,33}\end{array}$ & NR & 400 mg IV q12-24h & 400 mg IV q24h \\
\hline Colistimethate & $2-3 \mathrm{mg} / \mathrm{kg}$ IV q12-48h, & $2-3 \mathrm{mg} / \mathrm{kg}$ IV q12h & $2-3 \mathrm{mg} / \mathrm{kg} \mathrm{IV} \mathrm{q12-48h}$ & NR \\
\hline Cotrimoxazole & $\begin{array}{c}2.5-10 \mathrm{mg} / \mathrm{kg}(\mathrm{TMP}) \mathrm{IV} \\
\mathrm{q} 12 \mathrm{~h}^{6,19,35}\end{array}$ & NR & $2.5-10 \mathrm{mg} / \mathrm{kg}$ IV q12h & 2.5-10 mg/kg IV q12h \\
\hline Cyclosporine & $3-5$ mg/kg per day IV ${ }^{36,37}$ & NR & NR & $100 \%$ usual dose \\
\hline Enoxaparin & $30 \mathrm{mg} \mathrm{SC} \mathrm{q12ht^{38 }}$ & NR & NR & NR \\
\hline Fluconazole & 800 mg IV/PO q24h 13,39-42 & $\begin{array}{c}500-600 \mathrm{mg} \text { IV/PO } \\
\text { q12h }\end{array}$ & $\begin{array}{c}200-800 \mathrm{mg} \mathrm{IV} / \mathrm{PO} \\
\mathrm{q} 24 \mathrm{~h}\end{array}$ & $\begin{array}{c}200-400 \mathrm{mg} \mathrm{IV} / \mathrm{PO} \\
\mathrm{q} 24 \mathrm{~h}\end{array}$ \\
\hline Ganciclovir & $\begin{array}{c}1.25-2.5 \mathrm{mg} / \mathrm{kg} \mathrm{IV} \\
\mathrm{q} 24 \mathrm{~h}^{6,43}\end{array}$ & NR & $\begin{array}{c}1.25-2.5 \mathrm{mg} / \mathrm{kg} \mathrm{IV} \\
\text { q24h or } 2.5 \mathrm{mg} / \mathrm{kg} \mathrm{IV} \\
\text { q12h }\end{array}$ & $\begin{array}{c}1.25-2.5 \mathrm{mg} / \mathrm{kg} \mathrm{IV} \\
\mathrm{q} 24 \mathrm{~h}\end{array}$ \\
\hline Gentamicin & $\begin{array}{c}1-2.5 \mathrm{mg} / \mathrm{kg} \mathrm{IV} \\
\mathrm{q} 24-48 \mathrm{~h}^{6,44}\end{array}$ & $\begin{array}{c}0.3-1.75 \mathrm{mg} / \mathrm{kg} \mathrm{IV} \\
\text { q12h‡ }\end{array}$ & $\begin{array}{c}1-2.5 \mathrm{mg} / \mathrm{kg} \mathrm{IV} \\
\mathrm{q} 24-48 \mathrm{~h}\end{array}$ & $1.7 \mathrm{mg} / \mathrm{kg} \mathrm{IV} \mathrm{q12-48h}$ \\
\hline Imipenem-cilastatin & 500 mg IV q6-8h',45 & 500 mg IV q6-8h & 500 mg IV q6-8h & $500 \mathrm{mg} \mathrm{IV} \mathrm{q6h}$ \\
\hline Levofloxacin & $\begin{array}{c}250-750 \mathrm{mg} \text { IV/PO } \\
\mathrm{q} 24 \mathrm{~h}^{6,32,46}\end{array}$ & NR & 250-750 mg IV/PO q24h & $500 \mathrm{mg}$ IV/PO q48h \\
\hline Linezolid & 600 mg IV/PO q12h47,48 & NR & NR & 600 mg IV/PO q12h \\
\hline Meropenem & $\begin{array}{c}500-1000 \mathrm{mg} \mathrm{IV} \\
\mathrm{q} 8-12 \mathrm{~h}^{6,49-56}\end{array}$ & 1000 mg IV q12h & $\begin{array}{l}500 \mathrm{mg} \text { IV q6-12h or } \\
1000 \mathrm{mg} \text { IV q8-12h }\end{array}$ & 1000-2000 mg IV q12h \\
\hline Metronidazole & 500 mg IV q6-12h ${ }^{6,21}$ & 500 mg IV q6-12h & NR & 250-500 mg IV q8-12h \\
\hline Moxifloxacin & 400 mg IV/PO q24h ${ }^{57,58}$ & NR & NR & 400 mg IV/PO q24h \\
\hline Phenytoin & $\begin{array}{l}5-7 \mathrm{mg} / \mathrm{kg} \text { per day IV } \\
\text { divided q8-12h }\end{array}$ & $100 \%$ usual dose & NR & $100 \%$ usual dose \\
\hline Piperacillin-tazobactam & $\begin{array}{c}2.25-3.375 \mathrm{~g} \mathrm{IV} \\
\text { q6-8h }\end{array}$ & NR & NR & $4.5 \mathrm{~g} \mathrm{IV} \mathrm{q8h}$ \\
\hline Ranitidine & $\begin{array}{l}50 \mathrm{mg} \text { IV Q12h or } \\
150 \mathrm{mg} \text { PO q24h }\end{array}$ & NR & NR & 150 mg PO q12-24h \\
\hline Tacrolimus & $\begin{array}{l}0.03-0.04 \mathrm{mg} / \mathrm{kg} \\
\text { per day IV }\end{array}$ & NR & NR & NR \\
\hline Ticarcillin-clavulanate & $2-3.1 \mathrm{~g}$ IV q6-8h 6 6,64 & NR & NR & $3.1 \mathrm{~g} \mathrm{IV} \mathrm{q8-12h}$ \\
\hline Tobramycin & $\begin{array}{c}1-2.5 \mathrm{mg} / \mathrm{kg} \text { IV } \\
\text { q24-48h }\end{array}$ & $\begin{array}{l}0.3-1.75 \mathrm{mg} / \mathrm{kg} \\
\text { IV q12hf }\end{array}$ & $1-2.5 \mathrm{mg} / \mathrm{kg}$ IV q24-48h & $1.7 \mathrm{mg} / \mathrm{kg}$ IV q24-48h \\
\hline Vancomycin & $\begin{array}{l}7.5-15 \mathrm{mg} / \mathrm{kg} \mathrm{IV} \\
\text { q12-48h }\end{array}$ & $\begin{array}{l}500 \mathrm{mg} \text { IV q24-48h or } \\
1000 \text { mg IV q48h§ }\end{array}$ & $\begin{array}{c}10-15 \mathrm{mg} / \mathrm{kg} \mathrm{IV} \\
\text { q24-48h or } \\
7.5-10 \mathrm{mg} / \mathrm{kg} \mathrm{IV} \mathrm{q12h}\end{array}$ & 1000 mg IV q24-96h§ \\
\hline Voriconazole & $\begin{array}{l}400 \mathrm{mg} P O \mathrm{q} 12 \mathrm{~h} \times 2 \\
\text { then } 200 \mathrm{mg} P O \mathrm{q} 12 \mathrm{~h}^{13,70}\end{array}$ & NR & $\begin{array}{l}\text { No adjustment needed; } \\
\text { use PO }\end{array}$ & $100 \%$ usual dosage \\
\hline \multicolumn{5}{|c|}{$\begin{array}{l}\text { CIVI = continuous IV infusion; DPRF5 = Drug Prescribing in Renal Failure, 5th edition; NR = no dosage reported; TMP = trimethoprim. } \\
\text { ^No CRRT drug dosage recommendations in American Hospital Formulary System-Drug Information. } \\
\text { †For prophylaxis of venous thromboembolism. } \\
\text { †30\%-70\% of usual dose recommended. } \\
\text { §Assume } 70-\mathrm{kg} \text { body weight. }\end{array}$} \\
\hline
\end{tabular}


CRRT, the quality of existing data may not meet the editorial standards required for inclusion in the AHFS-DI monographs. For example, a recent systematic review of pharmacokinetic studies involving patients with sepsis who were receiving CRRT revealed that a significant proportion of studies failed to provide key information that readers would need to design an antimicrobial dosage regimen for their patients. ${ }^{71}$ Also, the US Food and Drug Administration (FDA) does not require manufacturers to perform research addressing the role of renal function on drug dosage. ${ }^{72}$ Although the FDA has produced a draft guidance document for industry covering study design, analysis, and impact on dosage and labelling for various degrees of renal dysfunction, ${ }^{73}$ the final recommendations, once released, will be nonbinding. These factors, combined with the reality that CRRT is a relatively rare medical intervention, may explain the absence of recommendations in the AHFS-DI.

Both DRUGDEX and Martindale provided drug dosage recommendations for less than half of the medications considered in this study. These drug information databases fall under the umbrella of the Micromedex 2.0 application. Information provided in the Micromedex 2.0 databases results from comprehensive, ongoing review of recommendations published in the world's medical journals, performed by in-house editorial staff. ${ }^{8}$ The editorial process consists of 5 steps: identification of literature and topics for discussion, creation of content, internal review of content, review by the Micromedex editorial board, and final clinical review and approval..$^{74}$ Perhaps the relative paucity of drug dosage recommendations for CRRT in the DRUGDEX and Martindale databases can be explained by the low volume of high-quality CRRT pharmacokinetic studies. ${ }^{11,71}$ Given that the Micromedex query field searches both databases, it is reassuring that the application yielded recommendations for a total of about two-thirds of the medications examined. Furthermore, both of the component databases in Micromedex provided concordant recommendations for the majority of medications, which suggests that their recommendations are reliable for use in clinical practice. In fact, the Martindale resource often cited an evidence-based review that was used in creating our reference standard recommendations. ${ }^{6}$

The most recent edition of the DPRF, the DPRF5, provided drug dosage recommendations for most of the medications considered in this study. Three of the 6 medications without CRRT dosage recommendations (liposomal amphotericin, basiliximab, and colistimethate) did not appear in the DPRF5's index, and therefore no dosage recommendations for any degree of renal dysfunction were provided. Although dosing of amphotericin and basiliximab does not change in the setting of CRRT, we believe that this information should be stated in tertiary drug information resources, to eliminate guesswork. The fluconazole dosage recommendation in the
DPRF5 was lower than the reference standard recommendation and constituted the only discordant recommendation in this resource.

The 21st century has brought with it a movement toward electronic point-of-care drug information resources. The wide variety of smartphone-based drug information applications and Internet-based resources now available may lessen the relevance of the current analysis in today's health care environment. However, 2 of the databases evaluated were Internet-based, and a third was available both in print and via the Internet. We did not evaluate the Internet version of the DPRF, which includes revised prescribing suggestions intended to account for the possibility that printed compendiums of drug dosage recommendations are out of date by the time they are published. ${ }^{75}$ Other comprehensive electronic tertiary resources that are frequently used, such as the Clinical Pharmacology database maintained by Elsevier, were not evaluated but may contain drug dosage recommendations for CRRT that reflect the most current evidence.

Several limitations to this study merit consideration. Drug dosage recommendations for CRRT should not be considered in terms of "one size fits all". Multiple factors influence the selection of a particular drug dosage during CRRT, such as the drug's physicochemical and pharmacokinetic properties, the mode of CRRT, the CRRT dose prescribed, circuit downtime, filter type and size, and the patient's residual renal function. ${ }^{76}$ Irrespective of the effects of CRRT, a number of other patientrelated factors during critical illness may alter the pharmacokinetic disposition of many drugs and the dosage required to achieve desired goals. For example, the early stages of multiple organ dysfunction syndrome are often associated with an increased volume of distribution for many antimicrobials, ${ }^{77}$ which may necessitate the administration of higher-than-usual initial doses to achieve the desired pharmacokinetic-pharmacodynamic goals. ${ }^{77}$ The heterogeneity surrounding CRRT techniques, equipment, and patient factors that could alter the pharmacokinetic parameters of many drugs, combined with relatively low number of patients who are exposed to this therapy, has undoubtedly contributed to the lack of drug dosage recommendations in tertiary resources. The evidencebased reference standard dosage recommendations generated for this study encompassed a wide variety of CRRT modes, equipment, and doses, and the discordant dosage recommendations observed in this study may be explained by this variety. Ideally, we would have preferred to evaluate the concordance of dosage recommendations stratified by each venovenous mode of CRRT, but the paucity of relevant published studies made this approach infeasible. When evaluating concordance, we did allow for wide variation in dosage recommendations because of the heterogeneity of the modes and dosage of CRRT used in each study. This allowance may have resulted in an overestima- 
tion of concordance, and it should be emphasized that drug dosage recommendations in CRRT should be tailored to the CRRT prescription and patient-related variables. Importantly, the reference standard dosing recommendations developed for this analysis were derived from pharmacokinetic studies that did not evaluate the association between dosage during CRRT and clinically important outcomes. The unproven assumption was that the reference standard dosing recommendations would achieve desired clinical outcomes. Another factor that may limit the applicability of these results is the relatively small number of medications examined. It is conceivable that drug dosage recommendations for other medications administered to patients undergoing CRRT are included in the drug information resources assessed and that they are concordant with recommendations in the primary and secondary literature. The clinical relevance of the sample of medications assessed in this study may also be questioned according to the importance of renal function in the elimination of each medication and their respective therapeutic windows. ${ }^{71}$ However, this does not appear to have been a major factor in the current study, because the kidney is a significant route of elimination for the majority of medications examined. Only one nonblinded investigator evaluated whether the dosage recommendations in the tertiary references were concordant with the reference standard dosage recommendations. Duplicate extraction and assessment by a second investigator could have reduced the risk of errors. Blinding of the data extraction and assessment processes would also have reduced the risk of bias. Finally, only 2 of the drug information databases contained within the Micromedex 2.0 application were evaluated. Other databases contained within this comprehensive application may have included dosing information for drugs administered to patients undergoing CRRT. However, if this information does exist, it may not be readily found by clinicians performing a quick search of the application.

\section{CONCLUSIONS}

One prominent North American tertiary drug information resource did not provide drug dosage recommendations for 33 medications that may be prescribed for patients receiving CRRT. However, 2 drug information databases contained within a comprehensive medical information application and the latest edition of a tertiary drug information resource that specializes in drug dosage recommendations for various degrees of renal dysfunction provided recommendations for many of the medications. For the most part, the recommended dosage regimens provided by these drug information resources were consistent with recommendations derived from the primary and secondary literature. Given the frequency and accuracy of recommendations in the most recent edition of DPRF (DPRF5), we recommend that it be used as the preferred reference for selection of drug dosage regimens during CRRT.
References

1. Afshinnia F, Straight A, Li Q, Slinin Y, Foley RN, Ishani A. Trends in dialysis modality for individuals with acute kidney injury. Ren Fail 2009;31(8):647-654.

2. Rabindranath KS, Adams J, MacLeod AM, Muirhead N. Intermittent versus continuous renal replacement therapy for acute renal failure in adults. Cochrane Database Syst Rev 2007;(3):CD003773.

3. Trotman RL, Williamson JC, Shoemaker DM, Salzer WL. Antibiotic dosing in critically ill patients receiving continuous renal replacement therapy. Clin Infect Dis 2005;41(8):1159-1166.

4. Schetz M. Drug dosing in continuous renal replacement therapy: general rules. Curr Opin Crit Care 2007;13(6):645-651.

5. Kuang D, Verbine A, Ronco C. Pharmacokinetics and antimicrobial dosing adjustment in critically ill patients during continuous renal replacement therapy. Clin Nephrol 2007;67(5):267-284.

6. Heintz BH, Matzke GR, Dager WE. Antimicrobial dosing concepts and recommendations for critically ill adult patients receiving continuous renal replacement therapy or intermittent hemodialysis. Pharmacotherapy 2009;29(5):562-577.

7. McEvoy GK, editor. AHFS drug information 2010. Bethesda (MD): American Society of Health-System Pharmacists; 2010 [cited 2011 Jun 6]. Accessed via MedicinesComplete subscription service, Pharmaceutical Press, London, UK.

8. Micromedex 2.0 (Micromedex Healthcare Series) [Internet database]. Greenwood Village (CO): Thomson Reuters (Healthcare) Inc; updated periodically [cited 2011 Jun 6]. Available from: www.thomsonhc.com/ micromedex $2 /$ librarian

9. Aronoff GR, Bennett WM, Berns JS, Brier ME, Kasbekar N, Mueller BA, et al, editors. Drug prescribing in renal failure: dosing guidelines for adults and children. 5th ed. Philadelphia (PA): American College of Physicians, 2007.

10. Vidal L, Shavit M, Fraser A, Paul M, Leibovici L. Systematic comparison of four sources of drug information regarding adjustment of dose for renal function. BMJ 2005;331(7511):263-266.

11. Mueller BA, Smoyer WE. Challenges in developing evidence-based drug dosing guidelines for adults and children receiving renal replacement therapy [editorial]. Clin Pharmacol Ther 2009;86(5):479-482.

12. Welling PG. Differences between pharmacokinetics and toxicokinetics. Toxicol Pathol 1995;23(2):143-147.

13. Fish DN. Antifungal dosing in dialysis and continuous renal replacement therapy. Curr Fungal Infect Rep 2011;5(2):75-82.

14. DRUGDEX System [Internet database]. Greenwood Village (CO) Thomson Reuters (Healthcare) Inc; updated periodically [cited 2011 Jun 6]. Available from: http://thomsonreuters.com/products_services/ healthcare/healthcare_products/a-z/drugdex_system/

15. Sweetman S, editor. Martindale: the complete drug reference [Internet database\}. London (UK): Pharmaceutical Press. Electronic version, Greenwood Village (CO): Thomson Reuters (Healthcare) Inc; updated periodically [cited 2011 Jun 6]. Available from: http:// thomsonreuters.com/products_services/healthcare/healthcare_products/ a-z/martindale/

16. Repchinsky C, editor. CPS 2012: compendium of pharmaceuticals and specialties. Ottawa (ON): Canadian Pharmacists Association; 2012.

17. Gorman SK, Slavik RS, Lam S. Drug dosing recommendations for continuous renal replacement therapy in tertiary references: a critical appraisal [abstract]. Can J Hosp Pharm 2009;62(1):72.

18. Bleyzac N, Barou P, Massenavette B, Contamin B, Maire P, Berthier JC, et al. Assessment of acyclovir intraindividual pharmacokinetic variability during continuous hemofiltration, continuous hemodiafiltration, and continuous hemodialysis. Ther Drug Monit 1999;21(5):520-525.

19. Joos B, Schmidli M, Keusch G. Pharmacokinetics of antimicrobial agents in anuric patients during continuous venovenous haemofiltration. Nephrol Dial Transplant 1996;11(8):1582-1585.

20. Taccone FS, de Backer D, Laterre PF, Spapen H, Dugernier T, Delattre I, et al. Pharmacokinetics of a loading dose of amikacin in septic patients undergoing continuous renal replacement therapy. Int J Antimicrob Agents 2011;37(6):531-535.

21. Bouman CS, van Kan HJ, Koopmans RP, Korevaar JC, Schultz MJ, Vroom MB. Discrepancies between observed and predicted continuous venovenous hemofiltration removal of antimicrobial agents in critically ill patients and the effects on dosing. Intensive Care Med 2006;32(12):2013-2019.

22. Bellmann R, Egger P, Djanani A, Wiedermann CJ. Pharmacokinetics of amphotericin B lipid complex in critically ill patients on continuous veno-venous haemofiltration. Int J Antimicrob Agents 2004;23(1):80-83.

23. Tomlin M, Priestley G. Elimination of liposomal amphotericin by hemodiafiltration. Intensive Care Med 1995;21(8):699-700. 
24. Eguchi S, Yanaga K, Okudaira S, Miyamoto S, Itoh Y, Inuo H, et al. Immunodynamics of basiliximab in liver allograft recipient under continuous hemodiafiltration. Transplantation 2004;77(9):1472-1480.

25. Allaouchiche B, Breilh D, Jaumain H, Gaillard B, Renard S, Saux MC. Pharmacokinetics of cefepime during continuous venovenous hemodiafiltration. Antimicrob Agents Chemother 1997;41(11):2424-2427.

26. Malone RS, Fish DN, Abraham E, Teitelbaum I. Pharmacokinetics of cefepime during continuous renal replacement therapy in critically ill patients. Antimicrob Agents Chemother 2001;45(11):3148-3155.

27. Vos MC, Vincent HH, Yzerman EPF, Vogel M, Mouton JW. Drug clearance by continuous haemodiafiltration: results with the AN-69 capillary haemofilter and recommended dose adjustments for seven antibiotics. Drug Invest 1994;7(6):345-322.

28. Sato T, Okamoto K, Kitaura M, Kukita I, Kikuta K, Hamaguchi M. The pharmacokinetics of ceftazidime during hemodiafiltration in critically ill patients. Artif Organs 1999;23(2):143-145.

29. Mariat C, Venet C, Jehl F, Mwewa S, Lazarevic V, Diconne E, et al. Continuous infusion of ceftazidime in critically ill patients undergoing continuous venovenous haemodiafiltration: pharmacokinetic evaluation and dose recommendation. Crit Care 2006;10:R26.

30. Kroh UF, Lennartz H, Edwards DJ, Stoeckel K. Pharmacokinetics of ceftriaxone in patients undergoing continuous veno-venous hemofiltration. J Clin Pharmacol 1996;36(12):1114-1119.

31. Matzke GR, Frye RF, Joy MS, Palevsky PM. Determinants of ceftriaxone clearance by continuous venovenous hemofiltration and hemodialysis. Pharmacotherapy 2000;20(6):635-643.

32. Malone RS, Fish DN, Abraham E, Teitelbaum I. Pharmacokinetics of levofloxacin and ciprofloxacin during continuous renal replacement therapy in critically ill patients. Antimicrob Agent Chemother 2001; 45(10):2949-2954

33. Wallis SC, Mullany DV, Lipman J, Rickard CM, Daley PJ. Pharmacokinetics of ciprofloxacin in ICU patients on continuous veno-venous haemodiafiltration. Intensive Care Med 2001;27(4):665-672

34. Li J, Rayner CR, Nation RL, Deans R, Boots R, Widdecombe N, et al. Pharmacokinetics of colistin methanesulfonate and colistin in a critically ill patient receiving continuous venovenous hemodiafiltration [letter]. Antimicrob Agents Chemother 2005;49(11):4814-4815.

35. Curkovic I, Luthi B, Franzen D, Ceschi A, Rudiger A, Corti N. Trimethoprim/sulfamethoxazole pharmacokinetics in two patients undergoing continuous venovenous hemodiafiltration. Ann Pharmacother 2010;44(10):1669-1672

36. Munar MY, Doyle IC, Meyer MM. Cyclosporine and vancomycin disposition during continuous venovenous hemodiafiltration. Ann Pharmacother 1995;29(4):374-377.

37. Seay R, Munar MY. Cyclosporine and vancomycin disposition during continuous venovenous hemodiafiltration [letter]. Ann Pharmacother 1995;29(9):941.

38. Isla A, Gascon AR, Maynar J, Arzuaga A, Corral E, Martin A, et al. In vitro and in vivo evaluation of enoxaparin removal by continuous renal replacement therapies with acrylonitrile and polysulfone membranes. Clin Ther 2005;27(9):1444-1451.

39. Yagasaki K, Gando S, Matsuda N, Kameue T, Ishitani T, Hirano T, et al. Pharmacokinetics and the most suitable dosing regimen of fluconazole in critically ill patients receiving continuous hemodiafiltration. Intensive Care Med 2003;29(10):1844-1848.

40. Muhl E, Martens T, Iven H, Rob P, Bruch HP. Influence of continuous veno-venous haemodiafiltration and continuous veno-venous haemofiltration on the pharmacokinetics of fluconazole. Eur J Clin Pharmacol 2000;56(9-10):671-678

41. Valtonen M, Tiula E, Neuvonene PJ. Effect of continuous venovenous haemofiltration and haemodiafiltration on the elimination of fluconazole in patients with acute renal failure. J Antimicrob Chemother 1997;40(5):695-700.

42. Kishino S, Koshinami Y, Hosoi T, Suda N, Takekuma Y, Gandoh S, et al. Effective fluconazole therapy for liver transplant recipients during continuous hemodiafiltration. Ther Drug Monit 2001;23(1):4-8.

43. Gando S, Kameue T, Nanzaki S, Hayakawa T, Nakanishi Y. Pharmacokinetics and clearance of ganciclovir during continuous hemodiafiltration. Crit Care Med 1998;26(1):184-187.

44. Thomson AH, Grant AC, Rodger RSC, Hughes RL. Gentamicin and vancomycin removal by continuous venovenous hemofiltration. DICP 1991;25(2):127-129.
45. Fish DN, Teitelbaum I, Abraham E. Pharmacokinetics and pharmacodynamics of imipenem during continuous renal replacement therapy in critically ill patients. Antimicrob Agents Chemother 2005;49(6):2421-2428.

46. Guenter SG, Iven H, Boos C, Bruch HP, Muhl E. Pharmacokinetics of levofloxacin during continuous venovenous hemodiafiltration and continuous venovenous hemofiltration in critically ill patients. Pharmacotherapy 2002;22(2):175-183.

47. Kraft MD, Pasko DA, DePestel DD, Ellis JJ, Peloquin CA, Mueller BA Linezolid clearance during continuous venovenous hemodiafiltration: a case report. Pharmacotherapy 2003;23(8):1071-1075.

48. Mauro LS, Peloquin CA, Schmude K, Assaly R, Malhotra D. Clearance of linezolid via continuous venovenous hemodiafiltration. Am J Kidney Dis 2006; 47(6):e83-e86

49. Robatel C, Decosterd LA, Biollaz J, Eckert P, Schaller MD, Buclin T. Pharmacokinetics and dosage adaptation of meropenem during continuous venovenous hemodiafiltration in critically ill patients. J Clin Pharmacol 2003;43(12):1329-1340

50. Thalhammer F, Horl WH. Pharmacokinetics of meropenem in patients with renal failure and patients receiving renal replacement therapy. Clin Pharmacokinet 2000;39(4):271-279.

51. Valtonen M, Tiula E, Backman JT, Neuvonen PJ. Elimination of meropenem during continuous veno-venous haemofiltration and haemodiafiltration in patients with acute renal failure. I Antimicrob Chemother 2000; 45(5):701-704.

52. Giles LJ, Jennings AC, Thomson AH, Creed G, Beale RJ, McLuckie A. Pharmacokinetics of meropenem in intensive care unit patients receiving continuous veno-venous hemofiltration or hemodiafiltration. Crit Care Med 2000;28(3):632-637.

53. Schroeder TH, Krueger WA, Hansen M, Hoffmann E, Dieterich HJ, Unertl K. Elimination of meropenem by continuous hemo(dia)filtration: an in vitro one-compartment model. Int J ArtifOrgans 1999;22(5):307-312.

54. Meyer MM, Munar MY, Kohlhepp SJ, Bryant RE. Meropenem pharmacokinetics in a patient with multiorgan failure from meningococcemia undergoing continuous venovenous hemodiafiltration. Am J Kidney Dis 1999;33(4):790-795.

55. Krueger WA, Schroeder TH, Hutchison M, Hoffman E, Dieterich HJ, Heininger A, et al. Pharmacokinetics of meropenem in critically ill patients with acute renal failure treated by continuous hemodiafiltration. Antimicrob Agent Chemother 1998;42(9):2421-2424.

56. Bilgrami I, Roberts A, Wallis SC, Thomas J, Davis J, Fowler S, et al. Meropenem dosing in critically ill patients with sepsis receiving highvolume continuous venovenous hemofiltration. Antimicrob Agents Chemother 2010;54(7):2974-2978.

57. Fuhrmann V, Schenk P, Jaeger W, Ahmed S, Thalhammer F. Pharmacokinetics of moxifloxacin in patients undergoing continuous venovenous haemodiafiltration. J Antimicrob Chemother 2004;54(4):780-784.

58. Stass H, Buhrmann S, Mitchell A, Kubitza D, Moller JG, Kribben A, et al The influence of continuous venovenous haemodialysis on the pharmacokinetics of multiple oral moxifloxacin administration to patients with severe renal dysfunction. Br J Clin Pharmacol 2007;64(6):745-749.

59. Lau AH, Kronfol NO. Effect of continuous hemofiltration on phenytoin elimination. Ther Drug Monit 1994;16(1):53-57.

60. Arzuaga A, Isla A, Gascon AR, Maynar J, Corral E, Pedraz JL. Elimination of piperacillin and tazobactam by renal replacement therapies and AN69 and polysulfone hemofilters: evaluation of the sieving coefficient. Blood Purif 2006;24(4):347-354

61. Valtonen M, Tiula E, Takkunen O, Backman JT, Neuvonen PJ. Elimination of piperacillin/tazobactam combination during continuous venovenous hemofiltration and hemodiafiltration in patients with acute renal failure. J Antimicrob Chemother 2001;48(6):881-885.

62. Mulla H, Peek G, Upton D, Lin E, Loubani M. Plasma aluminum levels during sucralfate prophylaxis for stress ulceration in critically ill patients on continuous venovenous hemofiltration: a randomized, controlled trial. Crit Care Med 2001;29(2):267-271.

63. Kishino S, Takekuma Y, Sugawara M, Shimamura T, Furukawa H, Todo S, et al. Influence of continuous venovenous haemodiafiltration on the pharmacokinetics of tacrolimus in liver transplant recipients with small-for-size grafts. Clin Transplant 2003;17(5):412-416.

64. Lindsay CA, Bawdon R, Quigley R. Clearance of ticarcillin-clavulanic acid by continuous venovenous hemofiltration in three critically ill children, two with and one without concomitant extracorporeal membrane oxygenation. Pharmacotherapy 1996;16(3):458-462.

65. DelDot ME, Lipman J, Tett SE. Vancomycin pharmacokinetics in critically ill patients receiving continuous venovenous haemodiafiltration. $\mathrm{Br} J$ Clin Pharmacol 2004;58(3):259-268. 
66. Muhl E, Bundesen J, Iven H, Bruch HP. Measurement and calculation of the extracorporeal elimination of vancomycin during continuous venovenous hemodiafiltration and continuous venovenous hemofiltration in critically ill patients. J Intensive Care Med 2001;16(5):222-230.

67. Okada H, Konishi K, Matsuda S, Saruta T, Suzuki H. Pharmacokinetics of vancomycin in patients with multiple organ failure during continuous hemodiafiltration. Clin Exp Nephrol 1999;3(4):296-299.

68. Santre CH, Leroy O, Simon M, Georges H, Guery B, Beuscart C, et al. Pharmacokinetics of vancomycin during continuous hemodiafiltration. Intensive Care Med 1993;19(6):347-350.

69. van de Vijsel LM, Walker SAN, Walker SE, Yamashita S, Simor A Hladunewich M. Initial vancomycin dosing recommendations for critically ill patients undergoing continuous venovenous hemodialysis. Can J Hosp Pharm 2010;63(3):196-206.

70. Robatel C, Rusca M, Padoin C, Marchetti O, Liaudet L, Buclin T. Disposition of voriconazole during continuous veno-venous haemodiafiltration (CVVHDF) in a single patient. I Antimicrob Chemother 2004;54(1):269-270.

71. Li AM, Gomersall CD, Choi G, Tian Q, Joynt GM, Lipman J. A systematic review of antibiotic dosage regimens for septic patients receiving continuous renal replacement therapy: do current studies supply sufficient data? I Antimicrob Chemother 2009;64(5):929-937.

72. McEvoy GK. Dose adjustment in renal impairment. Response from AHFS Drug Information [letter]. BMJ 2005;331(7511):293.

73. Guidance for industry: pharmacokinetics in patients with impaired renal function - study design, data analysis, and impact on dosing and labeling. Revision 1. Rockville (MD): US Department of Health and Human Services, Food and Drug Administration, Center for Drug Evaluation and Research; 2010 Mar [cited 2010 Oct 12]. Available from: www.fda.gov/downloads/Drugs/GuidanceComplianceRegulatory Information/Guidances/UCM204959.pdf

74. Micromedex editorial workflow. Greenwood Village (CO): Thomson Reuters (Healthcare) Inc; [cited 2011 Jun 6]. Available from: www.micromedex.com/evidence/collateral/ed_process.pdf

75. Aronoff GR. Dose adjustment in renal impairment [letter]. BMJ 2005;331(7511):293-294.
76. Joy MS, Matzke GR, Armstrong DK, Marx MA, Zarowitz BJ. A primer on continuous renal replacement therapy for critically ill patients. Ann Pharmacother 1998;32(3):362-375.

77. Ulldemolins M, Roberts JA, Lipman J, Rello J. Antibiotic dosing in multiple organ dysfunction syndrome. Chest 2011;139(5):1210-1220.

Sean K Gorman, BSCPharm, ACPR, PharmD, is Clinical CoordinatorCritical Care, Pharmacy Department, Capital District Health Authority, and Associate Professor, College of Pharmacy, Dalhousie University, Halifax, Nova Scotia.

Richard S Slavik, PharmD, FCSHP, is Regional Manager-Pharmacy Professional Practice and Pharmacotherapeutic Specialist-Critical Care, Pharmacy Department, Interior Health Authority, and Clinical Professor, Faculty of Pharmaceutical Sciences, The University of British Columbia, Kelowna, British Columbia.

Stefanie Lam, PharmD, was, at the time of this study, a Senior Clinical Pharmacist, General Medicine, National University Hospital Singapore, Singapore. She is now a Clinical Pharmacist in the Antimicrobia Stewardship Program at the Jewish General Hospital, Montréal, Quebec.

\section{Address correspondence to:}

Dr Sean K Gorman

Pharmacy Department

Victoria General Hospita

1276 South Park Street

Halifax NS B3H 2 Y9

e-mail: sean.gorman@dal.ca

\section{Acknowledgements}

We thank Erin Francis, student in the Bachelor of Science (Pharmacy) program at the Dalhousie University College of Pharmacy, for her assistance with database entry and verification. 